\title{
Identification, Characterization, Pathogenicity, and Distribution of Verticillium alfalfae in Alfalfa Plants in China
}

\author{
Shan $\mathrm{Xu},{ }^{1}$ Michael J. Christensen, ${ }^{2}$ Rebecca Creamer, ${ }^{3}$ and Yan $\mathrm{Zhong} \mathrm{Li}^{1, \dagger}$ \\ ${ }^{1}$ State Key Laboratory of Grassland Agro-Ecosystems, College of Pastoral Agricultural Science and Technology, Lanzhou \\ University, Key Laboratory of Grassland Livestock Industry Innovation, Ministry of Agriculture and Rural Affairs, Engineering \\ Research Center of Grassland Industry, 730020 Lanzhou, China \\ ${ }^{2}$ Grasslands Research Centre (Retired), Palmerston North 4442, New Zealand \\ ${ }^{3}$ Department of Entomology, Plant Pathology, and Weed Science, New Mexico State University, Las Cruces, NM 88003, U.S.A.
}

\begin{abstract}
Verticillium wilt caused by Verticillium alfalfae results in severe production losses in alfalfa crops and is a Class A quarantined disease in China. During 2015 to 2017, 365 alfalfa fields from 21 locations in six provinces were surveyed, and 45 fields from three closely located sites in Gansu, China were found to have alfalfa plants with symptoms typical of Verticillium wilt, with disease incidence of 12.6 to $53.6 \%$. Isolates were identified to species using morphological characteristics and a maximum likelihood phylogeny of the concatenated partial sequences of actin, elongation factor, glyceraldehyde-3-phosphate dehydrogenase, and tryptophan synthase gene regions of Verticillium isolates. Isolation incidence was $93.9 \%$ from roots, $71.7 \%$ from stems, $66.1 \%$ from petioles, and

$32.2 \%$ from leaves of field-infected plants, indicative of systemic disease and sporadic distribution of this pathogen. In greenhouse tests, the pathogen infected seedlings and colonized vascular tissues when inoculated on seeds, on root tips, in soil, or in injured, but not uninjured, aerial tissues, causing systemic symptoms like those in the field and significant losses. Pathogenicity testing also revealed that five locally grown perennial legumes (stylo, milkvetch, sainfoin, white clover, and red clover) could host $V$. alfalfae, with a high virulence to milkvetch, sainfoin, and stylo. This study confirmed that $V$. alfalfae has become established in some regions of Gansu, China and that is a risk to the alfalfa industry in China.
\end{abstract}

Alfalfa (Medicago sativa L.), regarded as "the queen of forages," is an important perennial forage crop and feedstock, and it is the most widely and extensively cultivated forage legume in the world. Its popularity as a forage is owing to its high protein content, digestible fiber, and being a rich source of vitamins and minerals. Alfalfa is thus ideal for livestock and even human consumption (Jasjeet et al. 2011; Shi et al. 2017). In China, alfalfa was cultivated in $\sim 8.5 \times 10^{6} \mathrm{hm}^{2}$ in 2013, mainly in Gansu, Inner Mongolia, Xinjiang, Ningxia, Sichuan, and Yunnan provinces (He 2013; Shi et al. 2017). The cultivation of this plant has increased since then for use in integrated farming systems and as fodder, grazing, and ecological conservation thanks to policies that provide subsidies for grassland ecological protection and revitalization of alfalfa for dairy production.

Verticillium wilt is a destructive vascular disease, leading to significant yield losses of alfalfa (Atkinson 1981; Huang 2003). Yield losses can reach up to $50 \%$ within 3 years because of rapid pathogen spread in fields. This disease also shortens the productive life of alfalfa crops (Peaden et al. 1985). This disease was first reported in Sweden in 1918 (Hedlund 1923), and later, it was recognized as an important disease in northern temperate areas of Europe (Kreitlow 1962). The initial outbreak of Verticillium wilt in the United States and Canada threatened the alfalfa industry (Christen and Peaden 1981; Graham et al. 1977; Sheppard 1979); this disease was

\section{${ }^{\dagger}$ Corresponding author: Y. Z. Li; liyzh@1zu.edu.cn}

Funding: This research was financially supported by Agro-scientific Research in the Public Interest grant 201303057, China Agriculture Research System grant CARS-34, Yunnan Province High-Tech Talents Introduction Project grant 2012HA012, Fundamental Research Funds for the Central Universities grant lzujbky-2017-k02, Academician workstation of Zhibiao Nan (No. 2018IC074), and 111 Project grant B12002.

The author(s) declare no conflict of interest.

Accepted for publication 18 January 2019.

@ 2019 The American Phytopathological Society commonly found in cooler regions (Gordon et al. 1989), but it was also detected in warm dry regions (Erwin and Howell 1998; Howell and Erwin 1995). Verticillium wilt of alfalfa was reported from Japan (Sato 1994) and Iran (Ghalandar et al. 2004) in 1994 and 2004, respectively; however, there were no reports of the disease from other Asian countries until the report by Xu et al. (2016). Although wilting symptoms on alfalfa induced by Phytophthora root rot, Fusarium wilt, Anthracnose, and Gibellulopsis sp. (Verticillium nigrescens) may be confused with Verticillium wilt symptoms, none of these diseases produce $\mathrm{V}$-shaped lesions on leaf tips on symptomatic plants with stems that remain green accompanied by discolored vascular tissue, the typical symptoms of Verticillium wilt of alfalfa (Gilbert et al. 1988; Harvey 1982; Hu et al. 2011). In China, Verticillium wilt of alfalfa is a Class A quarantined disease, and Huang et al. (1999) reported that all 25 of the tested Chinese alfalfa cultivars were susceptible to this disease. Regulatory and phytosanitary measures were established to prevent Verticillium wilt from spreading into disease-free regions by means of infected seeds or hay. After the causal agent of Verticillium wilt from infected seeds or hay was introduced into a disease-free region, this disease could become established and spread between fields by many means. Conidia and infected debris can be spread by wind, water, and farm machinery, such as balers, mowers, and tractor wheels, and the pathogen can infect plants through cut stems and roots (Howard 1985). In addition, numerous species of insects, including pests, predators, and even pollinators, have been found to be effective vectors for acquiring and transporting the pathogen from infected alfalfa sites to neighboring or distant wilt-free fields in suitable condition (Huang 2003; Huang et al. 1983). In spite of regulatory measures, commercial alfalfa plants cultivated in Liuxin village, Minle County of western Gansu, China have exhibited typical symptoms of Verticillium wilt, with an average incidence of $45.3 \%$, and they were confirmed to be infected with Verticillium alfalfae in 2014 (Xu et al. 2016).

Verticillium albo-atrum was regarded to be the vascular wilt pathogen of alfalfa, and strains from infected plants were relatively host specific to alfalfa (Hedlund 1923). V. albo-atrum underwent taxonomic revision based on multigene phylogenetic systematics work, and this has clarified its relationship with Verticillium nonalfalfae 
(Inderbitzin et al. 2011a), a species with similar morphological characteristics. The species originally isolated from alfalfa is identified as $V$. alfalfae (Inderbitzin et al. 2011a). Previous reports of alfalfa infections by " $V$. albo-atrum" were likely caused by $V$. alfalfae, because $V$. albo-atrum sensu stricto has been reported only from potato (Solanum tuberosum) (Inderbitzin et al. 2011a). The alfalfa strain of $V$. albo-atrum was shown to have the ability to infect some leguminous crops and weed species by artificial inoculation, causing foliar symptoms characteristic of Verticillium wilt or not causing symptoms (Busch and Smith 1982; Howell and Erwin 1995), but the natural occurrence of this pathogen had never been confirmed from other crops or forage legumes (Inderbitzin et al. 2011a). However, V. alfalfae was reported from Catalpa bignonioides in Italy, which seems to be the first report of a natural nonalfalfa host (Kasson et al. 2014).

Although studies on the symptomatology, epidemiology, and lifecycle of Verticillium wilt of alfalfa caused by $V$. alfalfae have provided a better understanding of this disease, no detailed information has been reported regarding $V$. alfalfae isolated from alfalfa in China. V. alfalfae isolates from different geographical regions may have different characteristics resulting from adaptations to the local environmental conditions (Howell and Erwin 1995). To better understand the biology, epidemiology, associated losses, and distribution of Verticillium wilt of alfalfa in China, surveys and laboratory and greenhouse experiments were done. An extensive survey of alfalfa-growing regions in China was done to assess the distribution of this disease. The means of dissemination was assessed to determine if $V$. alfalfae specifically infects plants at the seed stage, from inoculum in soil, and through damaged and undamaged stems and leaflets as they develop, leading to systemic symptoms. We assessed the effect of temperature on the growth and colony characteristics of $V$. alfalfae strains from alfalfa. We also measured the growth of young seedlings and developing plants after artificial inoculation in a greenhouse to evaluate the losses resulting from infection of $V$. alfalfae. Five locally grown perennial legumes were used in pathogenicity tests to determine the host range of $V$. alfalfae.

\section{Materials and Methods}

Field survey. From July to October in 2015 to 2017, an extensive survey was conducted throughout the primary commercial alfalfaproducing regions of China. The majority of survey sites were selected in or around Liuxin village, where Verticillium wilt of alfalfa was first observed in this region (Xu et al. 2016). In addition, other regions with high population densities of alfalfa fields including Hutubi (in Xinjiang province), Jinta, Hexibao, Shuiyuan (Gansu), Zhaojue (Sichuan), Pingjibao (Ningxia), Xiaoshao (Yunnan), Shaerqin, and Arhorchin (Inner Mongolia), all distant from the initial source region, were also selected for surveying. Three sites at each location (village) were recorded using a handheld global positioning system. Fields ranging from 1,000 to $2,500 \mathrm{~m}^{2}$ at each site were chosen arbitrarily for the incidence survey. In each field, three to five spots $\sim 1 \mathrm{~m}^{2}$ in area were arbitrarily surveyed. The number of healthy plants and the number of potentially infected plants exhibiting foliar symptoms of Verticillium wilt, such as V-shaped yellow, pinkish brown sections on leaf tips, or wilt, were recorded for each field, and the proportion of symptomatic among the total number of plants was regarded as the disease incidence. We also walked around the entire field to gain an overall impression of the incidence and effect of Verticillium wilt. Five plants with wilted leaves in each surveyed field were cut at the base of stems and individually collected for confirmation of infection by $V$. alfalfae by isolation onto potato dextrose agar (PDA).

In addition, six whole plants (including roots, stems, and leaves) with typical symptoms of green stems with wilted leaves from fields that had alfalfa plants already ascertained to be infected by $V$. alfalfae (Xu et al. 2016) were uprooted and taken to a laboratory in 2015 to assess the presence and rate of isolation of $V$. alfalfae in different parts of alfalfa plants.

Pathogen isolation and morphological characterization. All stem samples collected from each field were thoroughly washed in running tap water, and each stem was randomly cut into several small sections about 0.5 to $1 \mathrm{~cm}$ in length using disinfected scalpels. These segments were surface sterilized by treating with $70 \%$ alcohol for $30 \mathrm{~s}$ and then, with $0.5 \%$ sodium hypochlorite for $1 \mathrm{~min}$. The tissue was then washed three to four times in sterile distilled water and dried on sterile paper. Finally, several thin segments of each stem were transferred to culture dishes containing PDA and incubated in the dark at $25^{\circ} \mathrm{C}$ for 10 to 15 days. Colony morphological characteristics of isolates obtained from tissues were noted at 15 days. The presence of yellow to yellowish gray colonies of $V$. alfalfae on PDA was further confirmation of Verticillium wilt. Pure colonies were obtained by transferring 1- to 2-mm hyphal tips onto fresh PDA plates. The hyphae, conidia, and the characteristic conidiophores were observed under a light microscope and photographed by a Canon PC1310 camera system. Thirty conidia and conidiophores of representative isolates were subsequently measured for length and width. Finally, isolates were stored in $25 \%$ glycerol at $-70^{\circ} \mathrm{C}$.

All six whole alfalfa plants from each of the known infected fields were washed free of soil, and from each plant, several tissue samples, including roots, stems, leaf petioles, and leaflets, were obtained using sterilized scissors. Tissue samples from each plant were surface sterilized as described above and cut into 0.5 - to $1-\mathrm{cm}$-long segments, and 10 thin sections cut from each tissue type were plated onto PDA plates. With stems, sections were cut from the bottom, middle, and top regions. After 5 days of incubation at $25^{\circ} \mathrm{C}$ in darkness, colonies obtained from these thin sections were counted, and the frequency of isolation of $V$. alfalfae from each type of tissue was determined by examining colony characteristics.

To assess the effect of temperature on fungal growth and colony characteristics of isolates, plugs of hyphae ( $4 \mathrm{~mm}$ in diameter) were removed from the edges of colonies of representative isolates on PDA and transferred in the center of $9-\mathrm{cm}$ petri dishes containing $\sim 15 \mathrm{ml}$ of PDA. Plates were incubated at seven temperatures (4, $10,15,20,25,30$, and $35^{\circ} \mathrm{C}$ ). The colony diameter was measured twice at right angles for each colony at intervals of 4 days over the course of 24 days. Four replicates of each representative isolate (LXLYZ-154, LM31, and YZ-1) were used at each temperature, and the experiments were conducted twice.

Seed health test from fields. To evaluate the level of seedborne $V$. alfalfae, seeds were obtained from alfalfa plants with stems displaying wilted leaves and other typical symptoms in crops before harvest in 2016. Collected seeds were cleaned and divided into two types, mature and immature, by examination with a stereoscope microscope. Approximately 200 seeds were randomly selected from each type and surface sterilized in $70 \%$ alcohol for $1 \mathrm{~min}$ and $2 \%$ sodium hypochlorite for $10 \mathrm{~min}$. Then, they were washed three times in sterile distilled water and dried on sterile paper. Twenty-five seeds of each type were aseptically placed into PDA-containing petri dishes with eight replicates. Plates were incubated for 4 days at $25^{\circ} \mathrm{C}$ in the darkness and then visually assessed for seed infection by counting and recording the number of seeds that produced colonies characteristics of $V$. alfalfae. Colonies of uncertain identity were transferred to fresh PDA plates for additional microscopic examination.

DNA extraction, amplification, sequencing, and phylogenetic analyses. Total genomic DNA of the three representative isolates from each location was extracted from fresh mycelia grown on PDA using the HP Fungal DNA Kit (D3195-01) produced by OMEGA Biotech Co. Ltd. All steps were done following the manufacturer's protocols. Polymerase chain reaction (PCR) was performed in a 2720 Thermal Cycler (Applied Biosystems) in a total volume of $25 \mu \mathrm{l}$. Four nuclear gene regions, including partial sequences of actin $(A C T)$, elongation factor $(E F)$, glyceraldehyde-3phosphate dehydrogenase $(G P D)$, and tryptophan synthase (TS), were selected for study, and each gene was amplified and sequenced using the primer pairs VActF/VActR for $A C T$, VEFf/VEFr for $E F$, VGPDf2/VGPDr for $G P D$, and VTs3f/VTs3r for $T S$. PCR reactions were used and conducted as described by Inderbitzin et al. (2011b). PCR products were visualized after electrophoresis on $1.0 \%$ agarose gels, and the positive products were purified and sequenced by Sangon Biotech. Sequence data were assembled with DNAman (version 5.2.2; LynnonBiosoft) and deposited in GenBank. Sequences were 
searched for similar sequences in the NCBI using the basic local alignment search tool.

Our sequences of $A C T, E F, G P D$, and $T S$ from three representative isolates from alfalfa from each location and the reference sequences of the Verticillium spp. from forage and crop species as described by Inderbitzin et al. (2011a) were selected for phylogenetic analyses. Gibellulopsis nigrescens from Anemone coronaria (Japan) was used as the outgroup. All of the sequences were aligned using MAFFT, and the alignments were manually adjusted where necessary (Katoh and Standley 2013). Tree topologies of $70 \%$ for single-locus datasets were compared to evaluate whether single-locus datasets should be concatenated for combined analyses (Mason-Gamer and Kellogg 1996). A concatenated multilocus alignment ( $A C T, E F, G P D$, and $T S$ ) was performed with Mesquite 2.75. Separate partitions were created for each gene to permit analyses of both individual genes and the combined dataset. Models of nucleotide substitution for each gene partition and maximum likelihood (ML) phylogeny were conducted using the IQ-Tree method (Nguyen et al. 2014) with 1,000 ultrafast bootstraps (Hoang et al. 2018). The final tree was visualized using FigTree.

Greenhouse pathogenicity tests. The ability of $V$. alfalfae to infect developing alfalfa seedlings was tested. Three representative geographical isolates (LXLYZ-154, LM31, and YZ-1) of V. alfalfae were compared by pathogenicity testing on alfalfa (local cultivar Longdong). In the preliminary study, 5-week-old healthy alfalfa plants were uprooted and washed, the roots tips were clipped to a length of $3 \mathrm{~cm}$, and three groups of 10 trimmed plants were immediately soaked in $150 \mathrm{ml}$ conidial suspension $\left(1 \times 10^{6}\right.$ conidia per $\left.1 \mathrm{ml}\right)$ of each of the three representative isolates for $20 \mathrm{~min}$. The conidial suspensions from each isolate, which were cultivated on PDA for 2 weeks at $25^{\circ} \mathrm{C}$, were prepared by adding sterile distilled water and scraping the cultures with a sterile scalpel. Ten plants with trimmed roots were soaked in sterile water for $20 \mathrm{~min}$ as controls. After inoculation, each plant was transplanted individually, with one plant in each pot that contained sterilized soil, and these were kept in an inoculation chamber at high humidity for $48 \mathrm{~h}$. Plants were then returned to the greenhouse and arranged randomly. Four weeks later, all three isolates were inducing severe foliar disease symptoms on inoculated alfalfa plants. Control plants remained healthy and symptomless. Comparative pathogenicity of the three isolates to alfalfa was assessed using a scale of 1 to 5 as follows: $1=$ no symptoms; $2=$ one or two leaflets chlorotic; $3=$ trifoliolates on one shoot chlorotic; $4=$ trifoliolates on more than one shoot chlorotic; $5=$ plant dead (Christen et al. 1983). V. alfalfae was reisolated from stems exhibiting foliar symptoms, confirming successful infection. No
$V$. alfalfae was reisolated from controls. Because there was no significant difference in terms of morphological and molecular features and virulence between these three isolates, isolate LXLYZ-154 was chosen as a representative isolate for additional greenhouse pathogenicity tests.

The first pathogenicity experiment was an assessment of the ability of $V$. alfalfae to infect seeds. Mature seeds (Longdong), free from $V$. alfalfae, were surface sterilized by immersion in $70 \%$ alcohol for $1 \mathrm{~min}$ and $2 \%$ sodium hypochlorite solution for $10 \mathrm{~min}$; then, they were washed three times in sterile distilled water and dried by placing on sterile filter paper. A conidial suspension of $1 \times 10^{6}$ conidia per $1 \mathrm{ml}$ of $V$. alfalfae isolate LXLYZ-154 was prepared from pure 2 -week-old PDA cultures. Fifty surfacesterilized seeds were immersed in $100 \mathrm{ml}$ of spore suspension for $20 \mathrm{~min}$. Another 50 surface-sterilized seeds were immersed in $100 \mathrm{ml}$ of sterilized water for $20 \mathrm{~min}$ as the control. Ten inoculated seeds were put into each of five water agar (WA) plates (similar to uninoculated control seeds). The 10 plates were incubated at $25^{\circ} \mathrm{C}$ in the dark. After incubation for 4 days, the germination rate was assessed for $V$. alfalfae-inoculated and control alfalfa seeds. The numbers of infected seedlings and symptoms were recorded after 10 days, and the lengths of hypocotyls and radicles were recorded as well.

A second pathogenicity experiment assessed the ability of $V$. alfalfae to infect developing alfalfa seedlings. Four-day-old seedlings were selected from germinating surface-sterilized seeds on WA plates. The root tips of 50 4-day-old seedlings were dipped for $20 \mathrm{~min}$ in $150 \mathrm{ml}$ of conidial suspension of strain LXLYZ154 adjusted to $1 \times 10^{6}$ conidia per $1 \mathrm{ml}$, and then, each seedling was transplanted into an individual pot containing $70 \mathrm{~g}$ sterilized vermiculite that had been saturated with sterilized water. For controls, the root tips of 50 seedlings were dipped in $150 \mathrm{ml}$ of sterilized water for $20 \mathrm{~min}$ and then transplanted as for the inoculated seedlings. Infected and control seedlings were kept in an inoculation chamber at high humidity for $48 \mathrm{~h}$, and then, they were placed on a greenhouse bench in a random position. All plants were watered as required. After 16 days in the greenhouse, numbers of infected and dead plants as well as the symptoms were recorded. The lengths of the stems and roots of inoculated plants and controls were measured. The stem of each inoculated plant and each control plant was surface sterilized and placed on PDA for reisolation of $V$. alfalfae to confirm pathogen identity.

The third pathogenicity experiment was an evaluation of the ability of $V$. alfalfae to infect mature seedlings in soil. Surface-sterilized seeds were grown individually in 9-cm-diameter pots containing

Table 1. Infected location and mean disease incidence of Verticillium wilt (VW) of alfalfa in six provinces during 2015 to $2017 \mathrm{w}$

\begin{tabular}{|c|c|c|c|c|c|c|}
\hline \multirow[b]{2}{*}{ Location of field } & \multirow[b]{2}{*}{ Province } & \multicolumn{2}{|c|}{ Survey fields } & \multicolumn{3}{|c|}{ Mean disease incidence $(\%)$ of fields ${ }^{x}$} \\
\hline & & VW fields & Total fields & 2015 & 2016 & 2017 \\
\hline Liuxin (Minle)y & Gansu & 18 & 47 & $48.37 \pm 3.85^{z}$ & - & - \\
\hline Liuxin (Minle) & Gansu & 16 & 36 & - & $53.56 \pm 4.70$ & - \\
\hline Lemin (Minle) & Gansu & 9 & 32 & - & $24.02 \pm 3.57$ & - \\
\hline Yezhuang (Minle) & Gansu & 0 & 23 & $\mathrm{~N}$ & - & - \\
\hline Yezhuang (Minle) & Gansu & 2 & 13 & - & $12.60 \pm 2.95$ & - \\
\hline Taihe, Wenguang, Kaifaqu, Hejiagou (Minle) & Gansu & 0 & 40 & $\mathrm{~N}$ & - & - \\
\hline Xinpu, Yuzhuang, Songyin, Shuanglei (Minle) & Gansu & 0 & 35 & - & $\mathrm{N}$ & - \\
\hline Jinta (Jiuquan); Shuiyuan, Hexibao (Yongchang) & Gansu & 0 & 37 & - & $\mathrm{N}$ & - \\
\hline Xiaoshao (Kunmin) & Yunnan & 0 & 16 & - & - & $\mathrm{N}$ \\
\hline Zhaojue (Xichang); Mengyang (Chengdu) & Sichuan & 0 & 23 & - & - & $\mathrm{N}$ \\
\hline Pingjibao (Yinchuan) & Ningxia & 0 & 26 & - & - & $\mathrm{N}$ \\
\hline Hutubizheng (Changji) & Xinjiang & 0 & 10 & - & - & $\mathrm{N}$ \\
\hline Shaerqin (Hohhot); Arhorchin (Chifeng) & Inner Mongolia & 0 & 27 & - & - & $\mathrm{N}$ \\
\hline Total & 6 & 45 & 365 & & & \\
\hline
\end{tabular}

${ }^{\mathrm{w}} \mathrm{N}$, no foliar wilt symptoms of $\mathrm{VW} ;-$, not tested.

${ }^{x}$ Disease incidence is the percentage of plants surveyed that showed symptoms of VW.

y The name of the location surveyed; the village from the county or city is in parentheses.

$\mathrm{z}$ The values represent the average \pm standard error of VW fields in each location. 
$300 \mathrm{~g}$ soil that had been sterilized by gamma radiation (McLaren et al. 1962), and each pot was placed in a 12-cm-diameter tray. All plants were grown in a greenhouse, where temperatures ranged from $25^{\circ} \mathrm{C}$ during the day to $20^{\circ} \mathrm{C}$ at night. A total of 20 seedlings were grown for 5 weeks, and then, shoots were trimmed to a height of $3 \mathrm{~cm}$ above the soil surface. Water and Hollander nutrient solution were supplied as required to each pot. After another 5 weeks, $40 \mathrm{ml}$ of conidial suspension $\left(1 \times 10^{6}\right.$ conidia per $\left.1 \mathrm{ml}\right)$ of strain LXLYZ-154 was gently applied to the soil in each of 10 pots. Sterile water $(40 \mathrm{ml})$ was applied to each of 10 pots as control plants. When conducting the pathogenicity test, the pots were drenched with sterilized water before inoculation, and all inoculated and control pots were kept in an inoculation chamber at high humidity (100\%) for $48 \mathrm{~h}$ and then returned to the greenhouse bench in a random position. After 4 weeks, plants were evaluated visually for severity of foliar symptoms and scored for disease severity as described above. After measuring the lengths and fresh weights of roots and shoots of inoculated and control plants, the stem of each symptomatic and symptomless inoculated plant was used for reisolation of $V$. alfalfae on PDA. Thin transverse sections of stems of inoculated and control seedlings were hand cut, stained with aniline blue, and examined using a compound microscope for the presence of hyphae in vascular bundles. All greenhouse pathogenicity tests were conducted twice to ensure consistency of results of $V$. alfalfae infection of alfalfa.

Wounding effects on infection by $V$. alfalfae. Two experiments on the effects of tissue wounding on the infection by $V$. alfalfae were carried out. The first experiment involved two treatments, one of which was with uninjured leaves and the other was with leaves injured by piercing 10 times on the adaxial surface. Thirty healthy 5week-old seedlings were used for this experiment, and the growing conditions were as described above. Three locations of uninjured leaflets from different petioles midway up the stem on 10 plants were inoculated by the placing on them using a pipette one or two 5- $\mu l$ drops of a conidial suspension $\left(10^{6}\right.$ conidia per $1 \mathrm{ml}$ from LXLYZ-154). In addition, three injured leaflets were inoculated in the same way and with the same replications. Three injured and three uninjured leaflets of five plants were treated with sterile water as controls.

In a second experiment, the stem of each of 10 plants was removed above the petiole of the second trifoliate leaf using disinfected scissors, and then, a 5- $\mu 1$ drop of inoculum was transferred immediately to the cut surface with a fine brush. Ten intact plants were inoculated at the same height of the stem by applying $5 \mu$ l of inoculum onto the stem surface with a fine brush. Five plants had a similar quantity of sterile water applied to either the cut stem or the undamaged stem as controls.

When performing the inoculation studies, all plants were placed in an inoculation chamber with $100 \%$ relative humidity for 3 to 4 days, and then, they were arranged randomly on a greenhouse bench with 60 to $80 \%$ relative humidity. A $100-\mathrm{ml}$ conidial suspension was obtained from 2-week-old PDA cultures and adjusted to $10^{6}$ conidia per $1 \mathrm{ml}$; one drop of Tween 20 was added to the $100-\mathrm{ml}$ suspension to ensure that the inoculum did not run off the tissues. After 4 weeks, 30 inoculated leaves, 30 junction petioles, and 10 stems were taken from plants of experiment 1 , in which leaves had been inoculated, as well as from control plants. These were surface sterilized, and pieces of each type of tissue were placed on WA plates to isolate $V$. alfalfae. With experiment 2, stem pieces at and below the inoculated sites of plants of each inoculation treatment and control plants were excised and similarly processed to detect the presence of V. alfalfae.

Host range study of $V$. alfalfae. Five locally grown perennial legumes, stylo (Stylosanthes guianensis), milkvetch (Astragalus adsurgens), sainfoin (Onobrychis viciaefolia), white clover (Trilolium repens), and red clover (Trilolium pratense), were used in this greenhouse study of the host range of the strain of $V$. alfalfae from
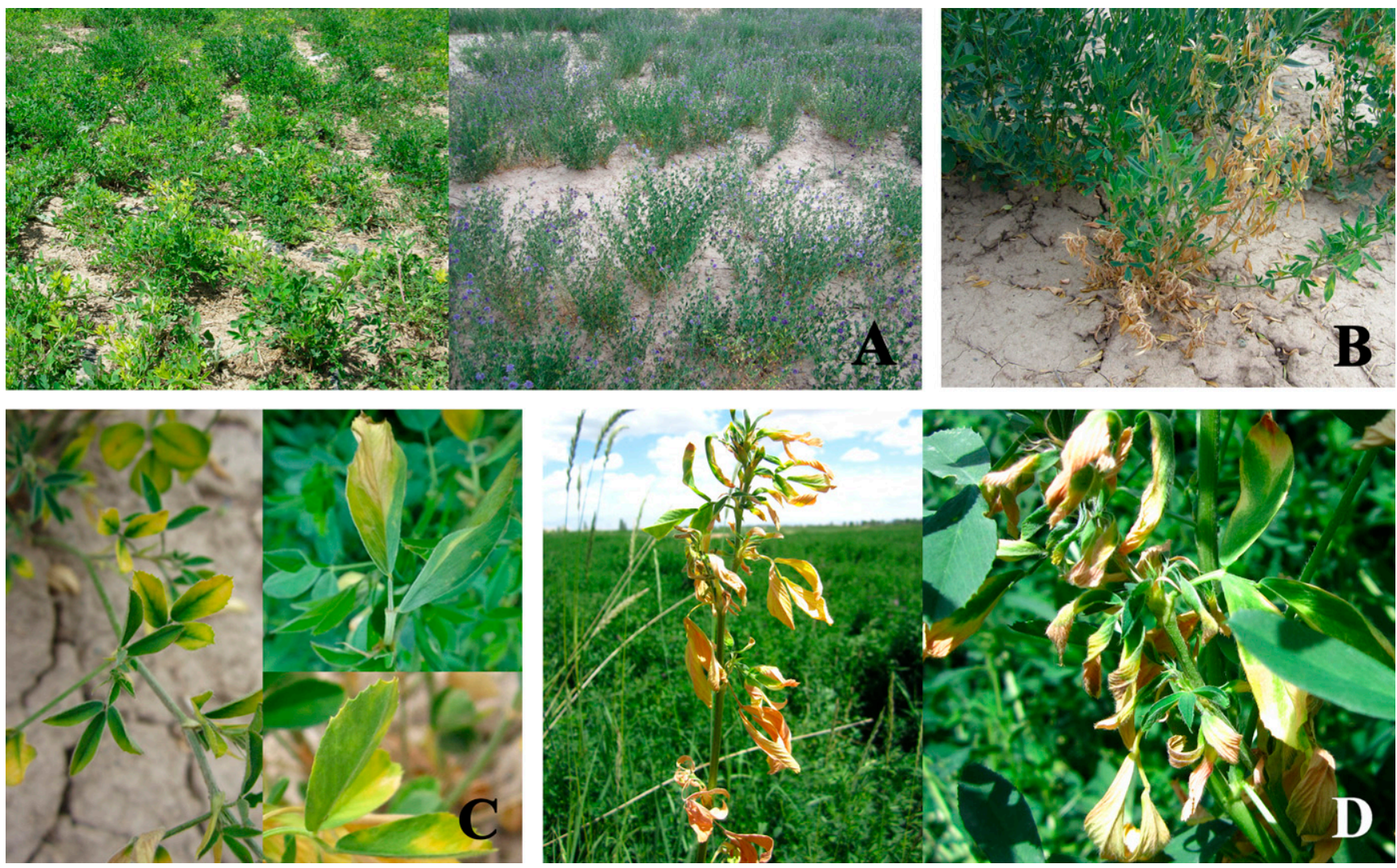

Fig. 1. Symptoms of Verticillium wilt of alfalfa. A, Infected plants occurred frequently or sporadically in the fields. B, A diseased plant with stunting and wilt symptoms. The diseased stem was green with severely wilting leaves. C, Chlorotic leaves with yellow blotchiness. Chlorotic leaves had V-shaped tips after disease progression. D, Chlorotic leaves tend to twist loosely or tightly along the midrib, and also, they remain open. 
local alfalfa plants. Ten 5-week-old seedlings of each plant species were removed from the soil in a pot, washed in tap water, inoculated by soaking the trimmed roots $(3$ to $4 \mathrm{~cm})$ in a conidial suspension ( $10^{6}$ conidia per $1 \mathrm{ml}$ from LXLYZ-154) for $20 \mathrm{~min}$, and replanted in the same pot. Another 10 seedlings of each plant species were soaked in sterile water for $20 \mathrm{~min}$ as uninoculated controls. The inoculated and control seedlings were placed in an inoculation chamber for 2 days; then, all plants were placed randomly on the greenhouse bench, where the conditions of the greenhouse were as described above. Four weeks later, all plants were evaluated for the presence
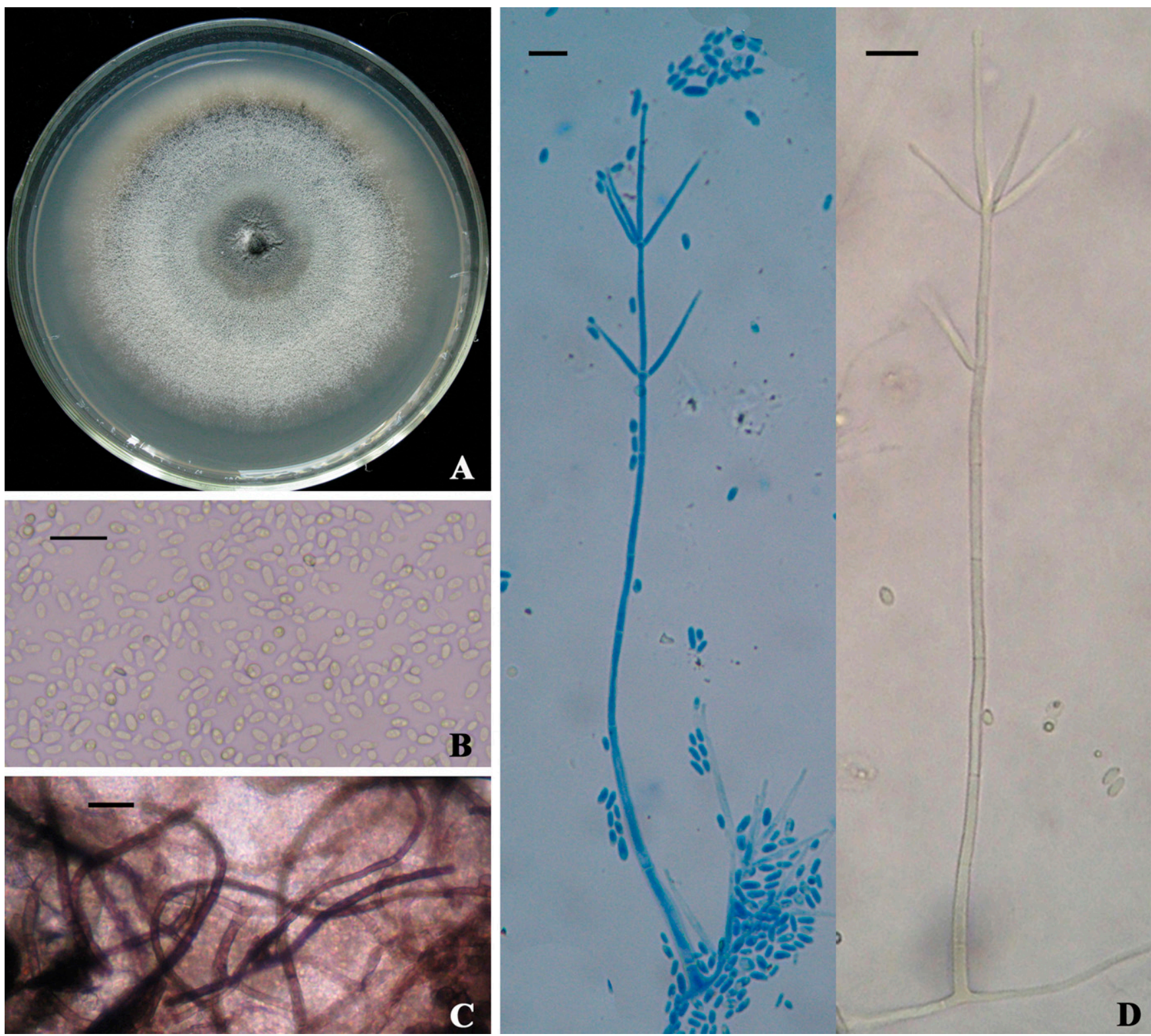

Fig. 2. Morphological features of Verticillium alfalfae (strain LXLYZ-154). A, Colony morphology on potato dextrose agar. B, Conidia. C, Resting mycelium. D, Conidiophore. Scale bars in B to $D$ are $20 \mu \mathrm{m}$.

Table 2. Growth rates of Verticillium alfalfae isolate LXLYZ-154 at varying temperatures ${ }^{\mathrm{y}}$

\begin{tabular}{|c|c|c|c|c|c|c|}
\hline \multirow[b]{2}{*}{ Days postinoculation } & \multicolumn{6}{|c|}{ Growth rate $(\mathrm{mm} / \text { day })^{\mathrm{z}}$} \\
\hline & $4^{\circ} \mathrm{C}$ & $10^{\circ} \mathrm{C}$ & $15^{\circ} \mathrm{C}$ & $20^{\circ} \mathrm{C}$ & $25^{\circ} \mathrm{C}$ & $30^{\circ} \mathrm{C}$ \\
\hline $0-4$ & $0.02 \pm 0.01$ & $0.97 \pm 0.01$ & $2.07 \pm 0.04$ & $2.83 \pm 0.05$ & $3.45 \pm 0.04$ & $0.68 \pm 0.00$ \\
\hline $4-8$ & $0.64 \pm 0.04$ & $1.25 \pm 0.01$ & $2.11 \pm 0.08$ & $3.10 \pm 0.05$ & $3.69 \pm 0.07$ & $0.50 \pm 0.00$ \\
\hline $8-12$ & $1.19 \pm 0.04$ & $1.29 \pm 0.04$ & $2.33 \pm 0.04$ & $3.31 \pm 0.06$ & $3.73 \pm 0.06$ & $0.69 \pm 0.01$ \\
\hline $12-16$ & $1.10 \pm 0.01$ & $2.58 \pm 0.08$ & $3.50 \pm 0.02$ & $3.47 \pm 0.03$ & $3.90 \pm 0.04$ & $0.44 \pm 0.01$ \\
\hline $16-20$ & $0.83 \pm 0.01$ & $2.05 \pm 0.01$ & $2.84 \pm 0.12$ & $3.09 \pm 0.08$ & $2.50 \pm 0.02$ & $0.29 \pm 0.02$ \\
\hline $20-24$ & $0.76 \pm 0.04$ & $1.84 \pm 0.04$ & $2.56 \pm 0.06$ & $2.90 \pm 0.04$ & $2.26 \pm 0.11$ & $0.25 \pm 0.01$ \\
\hline Per day & $0.76 \mathrm{e}$ & $1.66 \mathrm{~d}$ & $2.57 \mathrm{c}$ & $3.12 \mathrm{~b}$ & $3.26 \mathrm{a}$ & $0.47 \mathrm{f}$ \\
\hline
\end{tabular}

${ }^{y}$ The values represent the average \pm standard error of four replicates. Growth rates per day that were significant when analyzed by SAS Institute protocols with repeated measures analysis of variance $(P<0.01)$ are marked with different letters.

${ }^{\mathrm{z}}$ The growth rate at each temperature was calculated by dividing the colony diameter by the number of days. There was no growth at $35^{\circ} \mathrm{C}$. 
or absence of foliar symptoms, and isolations were conducted as above from the stems of inoculated plants to determine whether symptomatic or asymptomatic plants were infected with $V$. alfalfae.

Statistical analyses. The data of biomass between inoculated and healthy seeds and between developing and mature plants in the greenhouse were statistically analyzed using SPSS with the independent sample $t$ test at a significance level of $P=0.01$. The data of growth rate at different temperatures of LXLYZ-154 were evaluated according to SAS Institute protocols with repeated measures analysis of variance $(P=0.01)$.

\section{Results}

Symptoms, incidence, and distribution of Verticillium wilt. From 2015 to 2017, 365 fields from 21 regions of six provinces were surveyed, and 45 fields from Gansu were found to have alfalfa plants infected with Verticillium wilt based on plant symptoms followed by isolation of $V$. alfalfae (Table 1). All fields with alfalfa plants infected with $V$. alfalfae were in 3 regions in or around Liuxin village, whereas Verticillium wilt was not detected in another 11 regions of Gansu or in five other provinces. Two of 13 fields from Yezhuang village were found in 2016 to have alfalfa plants with Verticillium wilt, with an average incidence of $12.6 \%$, although no visible symptoms had been observed in that region in 2015 . The incidence of Verticillium wilt ranged from 8.4 to $71.7 \%$ in infected fields in Liuxin village. Infected plants were either frequently scattered or occurred sporadically in fields (Fig. 1A). Although wilt symptoms caused by Fusarium oxysporum or Colletotrichum trifolii were observed in Kaifaqu and Jinta, respectively, the symptoms of these diseases were clearly distinguishable from symptoms of
Verticillium wilt, and the causal pathogens were easily confirmed by isolation onto PDA.

The symptoms of infected alfalfa plants observed were wilting and stunting, and portions of stems on plants were symptomless. Although the leaves had severe wilting or were dead, the diseased stems were not wilted and remained green (Fig. 1B). Symptoms were initially a yellow blotchiness on leaflets, and then, yellow streaks developed along the midrib and veins on leaflets of a single stem or sometimes, leaflets of several stems of a plant. As the disease progressed, a characteristic V-shaped chlorosis developed on the tip of leaflets (Fig. 1C). Subsequently, young leaves twisted loosely or tightly along the midrib, and old leaves remained open (Fig. 1D). Finally, all infected leaves became necrotic and desiccated. Some leaflets with petioles attached to a green stem or leaflets that have fallen onto the ground developed a tan, yellow, or pinkish orange discoloration. The vascular tissues of all infected stems exhibited a brown discoloration.

Pathogen isolation and morphological characterization. $V$. alfalfae was isolated from the base of stems from each alfalfa plant sampled from each of the 45 fields in Gansu province, which confirmed the presence of Verticillium wilt. The pathogen was also isolated from the thin sections of roots, stems, petioles, and leaves of infected plants. Isolates were most frequently obtained from roots $(93.9 \%)$ and less frequently obtained from stems $(71.7 \%)$, and the frequency was lower as the distance up the stem increased; $66.1 \%$ of petiole sections and $32.2 \%$ of sections of leaves with chlorotic symptoms gave rise to $V$. alfalfae.

$V$. alfalfae isolates from three regions formed a consistent identical colony morphology on PDA at $25^{\circ} \mathrm{C}$. Initially colonies were white

Table 3. Strains of Verticillium spp. isolated from forage and crop species with collection details and GenBank accession numbers and the representative Verticillium alfalfae isolates from Medicago sativa in three sites in China (in bold) ${ }^{\mathrm{x}}$

\begin{tabular}{|c|c|c|c|c|c|c|c|}
\hline \multirow[b]{2}{*}{ Species } & \multirow[b]{2}{*}{ Accession name } & \multirow[b]{2}{*}{ Host } & \multirow[b]{2}{*}{ Location } & \multicolumn{4}{|c|}{ GenBank accessions } \\
\hline & & & & ACT & $\mathbf{E F}$ & GPD & TS \\
\hline Verticillium albo-atrum & PD670y & Solanum tuberosum & United States & JN188116 & JN188244 & JN188180 & JN188052 \\
\hline Verticillium albo-atrum & PD693 & Solanum tuberosum & United Kingdom & JN188122 & JN188250 & JN188186 & JN188058 \\
\hline V. alfalfae & PD489 & M. sativa & United States & JN188097 & JN188225 & JN188161 & JN188033 \\
\hline V. alfalfae & PD620 & M. sativa & Canada & HQ206965 & HQ414668 & HQ414763 & HQ414953 \\
\hline V. alfalfae & PD682 & M. sativa & Japan & JN188118 & JN188246 & JN188182 & JN188054 \\
\hline V. alfalfae & LXLYZ-154 & M. sativa & China (Gansu, Liuxin) & MH628610 & MH628637 & MH628619 & MH628628 \\
\hline$V$. alfalfae & LXLYZ-155 & M. sativa & China (Gansu, Liuxin) & MH628611 & MH628638 & MH628620 & MH628629 \\
\hline$V$. alfalfae & LXLYZ-156 & M. sativa & China (Gansu, Liuxin) & MH628612 & MH628639 & MH628621 & MH628630 \\
\hline$V$. alfalfae & YZ-1 & M. sativa & China (Gansu, Yezhuang) & MH628613 & MH628640 & MH628622 & MH628631 \\
\hline V. alfalfae & YZ-2 & M. sativa & China (Gansu, Yezhuang) & MH628614 & MH628641 & MH628623 & MH628632 \\
\hline$V$. alfalfae & YZ-3 & M. sativa & China (Gansu, Yezhuang) & MH628615 & MH628642 & MH628624 & MH628633 \\
\hline V. alfalfae & LM31 & M. sativa & China (Gansu, Lemin) & MH628616 & MH628643 & MH628625 & MH628634 \\
\hline$V$. alfalfae & LM32 & M. sativa & China (Gansu, Lemin) & MH628617 & MH628644 & MH628626 & MH628635 \\
\hline$V$. alfalfae & LM33 & M. sativa & China (Gansu, Lemin) & MH628618 & MH628645 & MH628627 & MH628636 \\
\hline Verticillium dahliae & PD322 & Lactuca sativa & United States & HQ206921 & HQ414624 & HQ414719 & HQ414909 \\
\hline Verticillium dahliae & PD327 & Capsicum аппиит & United States & HQ206925 & HQ414628 & HQ414723 & HQ414913 \\
\hline Verticillium nonalfalfae & PD592 & Solanum tuberosum & Japan & JN188099 & JN188227 & JN188163 & JN188035 \\
\hline Verticillium nonalfalfae & PD808 & Humulus lupulus & Slovenia & JN188148 & JN188276 & JN188212 & JN188084 \\
\hline Verticillium nubilum & PD742 & Soil & United Kingdom & JN188139 & JN188267 & JN188203 & JN188075 \\
\hline Verticillium nubilum & PD702 & Solanum tuberosum & United Kingdom & JN188123 & JN188251 & JN188187 & JN188059 \\
\hline Verticillium longisporum & PD687 allele A1 & Armoracia rusticana & Germany & HQ206993 & HQ414696 & HQ414791 & HQ414981 \\
\hline Verticillium longisporum & PD356 allele A1 & Armoracia rusticana & United States & HQ206934 & HQ414637 & HQ414732 & HQ414922 \\
\hline Verticillium isaacii & PD341 & Lactuca sativa & United States & JN188089 & JN188217 & JN188153 & JN188025 \\
\hline Verticillium isaacii & PD610 & Lactuca sativa & United States & JN188104 & JN188232 & JN188168 & JN188040 \\
\hline Verticillium klebahnii & PD347 & Cynara scolymus & United States & JN188091 & JN188219 & JN188155 & JN188027 \\
\hline Verticillium klebahnii & PD458 & Lactuca sativa & United States & JN188096 & JN188224 & JN188160 & JN188032 \\
\hline Verticillium tricorpus & PD593 & Solanum tuberosum & Japan & JN188100 & JN188228 & JN188164 & JN188036 \\
\hline Verticillium tricorpus & PD594 & Solanum lycopersicum & Japan & JN188101 & JN188229 & JN188165 & JN188037 \\
\hline Verticillium zaregamsianum & PD586 & Matthiola incana & Japan & JN188098 & JN188226 & JN188162 & JN188034 \\
\hline Verticillium zaregamsianum & PD740 & Matthiola incana & Japan & JN188137 & JN188265 & JN188201 & JN188073 \\
\hline Gibellulopsis nigrescens $^{\mathrm{z}}$ & PD595 & Anemone coronaria & Japan & JN188102 & JN188230 & JN188166 & JN188038 \\
\hline
\end{tabular}

${ }^{x}$ ACT, actin; EF, elongation factor; GPD, glyceraldehyde-3-phosphate dehydrogenase; TS, tryptophan synthase.

y PD identifiers are representative isolates of Verticillium species obtained from the studies by Inderbitzin et al. (2011a, 2011b).

${ }^{\mathrm{z}}$ G. nigrescens isolated from A. coronaria in Japan was used as the outgroup. 
and flat, and later, the center of colonies became somewhat yellowish and appressed with sparse aerial hyphae. Later, the abundant aerial hyphae were floccose to pruinose, and the colonies turned gray and became dark owing to the presence of resting mycelium apart from the white margin (Fig. 2A). Conidiophores were hyaline, or occasionally, they had a brown-pigmented base, contained several transverse septa that were vertical or slanted, contained whorled conidiogenous cells, and were 80.0 to $550.0 \times 4.2$ to $6.3 \mu \mathrm{m}$ in size (Fig. 2D). Conidiogenous cells were phialides 40 to $60 \mu \mathrm{m}$ in length, and the whorls included one to five phialides. Conidia produced from the heads of phialides were hyaline, aseptate, ovoid, or cylindrical with rounded ends (Fig. 2B), and they were 3.8 to $11.5 \times 1.6$ to $3.5 \mu \mathrm{m}$ in size. No microsclerotia were formed on plates, and only masses of brown hyphae were present (Fig. 2C).

Cultural growth evaluation revealed that there were no significant differences in growth rate at each temperature $(P>0.01)$ among isolates LXLYZ-154, LM31, and YZ-1 and that there were no visible differences in colony morphology among the three isolates at each temperature. The representative isolate LXLYZ-154 was able to grow at 4 to $30^{\circ} \mathrm{C}$ on PDA, but hyphal growth was negligible at $30^{\circ} \mathrm{C}$, and there was no growth at $35^{\circ} \mathrm{C}$. The average growth rates of strain LXLYZ-154 incubated at seven temperatures at 4-day intervals on PDA are shown in Table 2 . The growth rate, ranging from 0.76 to $3.26 \mathrm{~mm} /$ day at 4 to $30^{\circ} \mathrm{C}(F=2,689.38, P=0.000)$, was significantly affected by temperature alteration (Table 2 ). The optimum growth temperature was at $25^{\circ} \mathrm{C}$. The color of colonies was changed by temperature variation, and abundant dark resting mycelium was most common at $25^{\circ} \mathrm{C}$.
Seed infection assessment. $V$. alfalfae was isolated from some surface-sterilized mature or immature seeds that had been harvested from infected plants and incubated on PDA. The percentage of these surface-sterilized seeds that were infected was low, with just $1 \%$ of mature seeds and $5.5 \%$ of immature seeds giving rise to colonies of $V$. alfalfae. The majority of seeds collected from infected plants were not mature, whereas the majority of those from uninfected plants were mature.

Sequence and phylogenetic analyses. Alignment of sequences in the $A C T, E F, G P D$, and $T S$ regions of representative strains matched
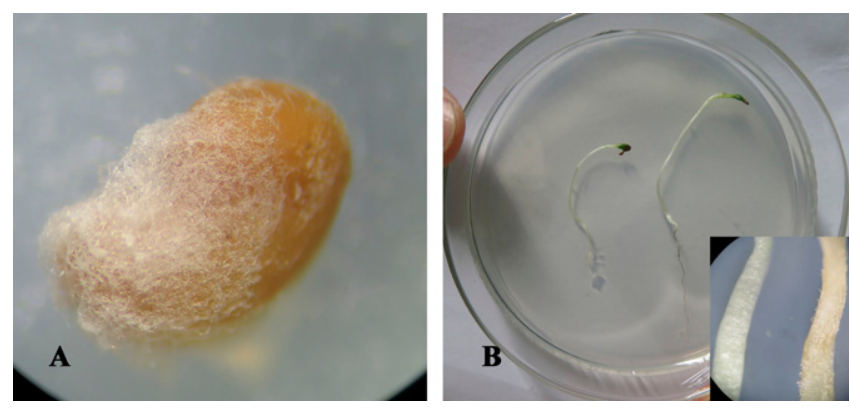

Fig. 4. Alfalfa seeds inoculated with Verticillium alfalfae after 10 days postinoculation. A, Seed inoculated with $V$. alfalfae conidia that did not germinate. B, The seedling on left is the control, and the seedling on the right with brown radicle was inoculated with $V$. alfalfae.

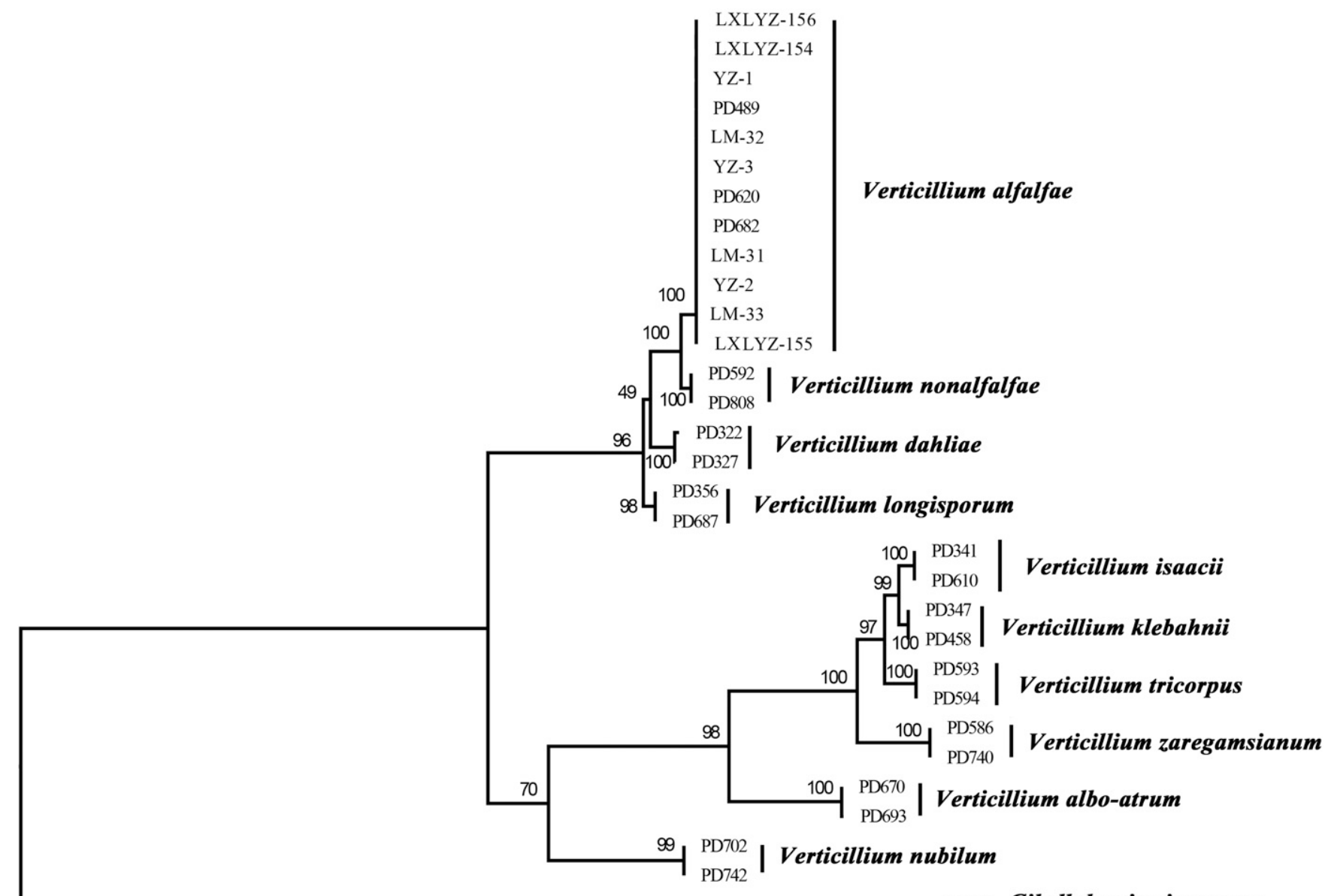

PD595 Gibellulopsis nigrescens

Fig. 3. A maximum likelihood phylogeny of the concatenated partial sequences of $A C T, E F, G P D$, and $T S$ gene regions (2,468 nucleotides) of Verticillium isolates used in this study. The numbers on the nodes are maximum likelihood bootstrap values based on a 1,000-ultrafast bootstrap support for IQ-Tree. Gibellulopsis nigrescens was used as the outgroup. 
A

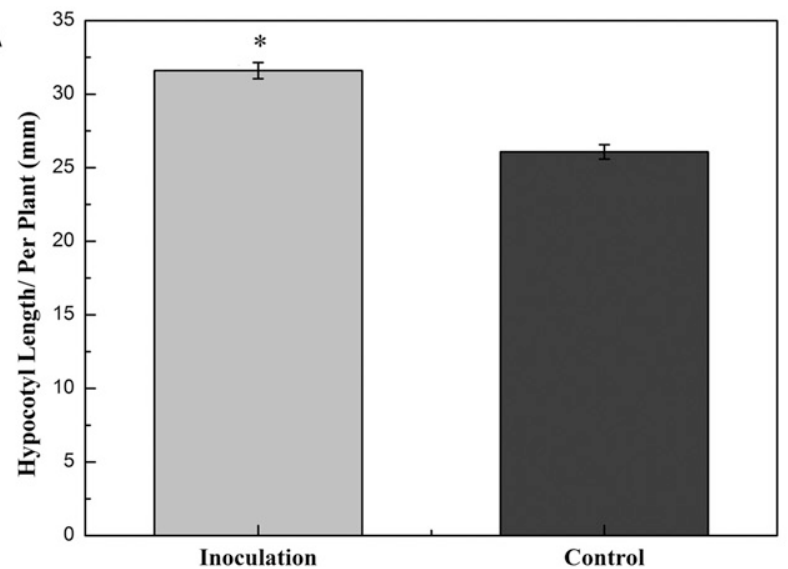

C

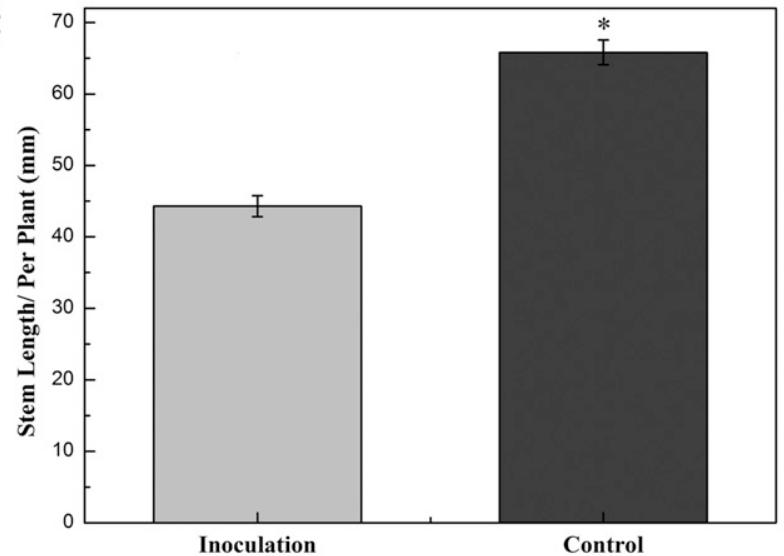

E

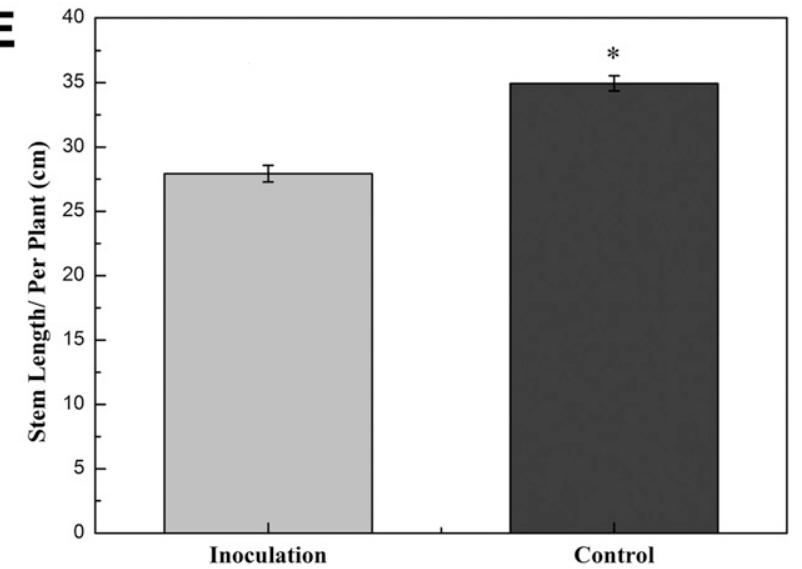

G

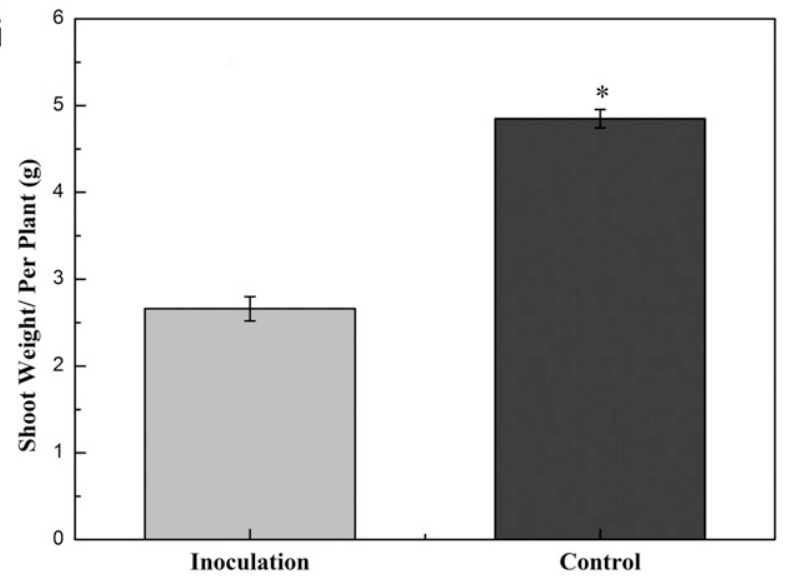

B

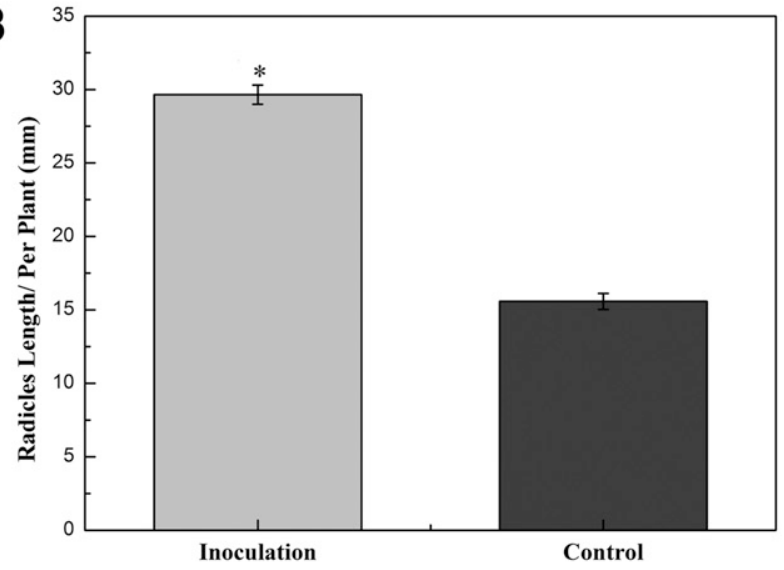

D

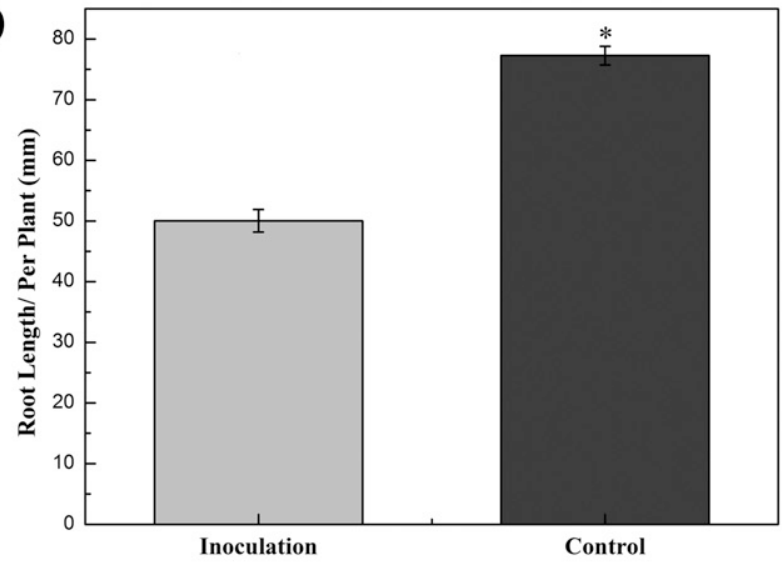

F

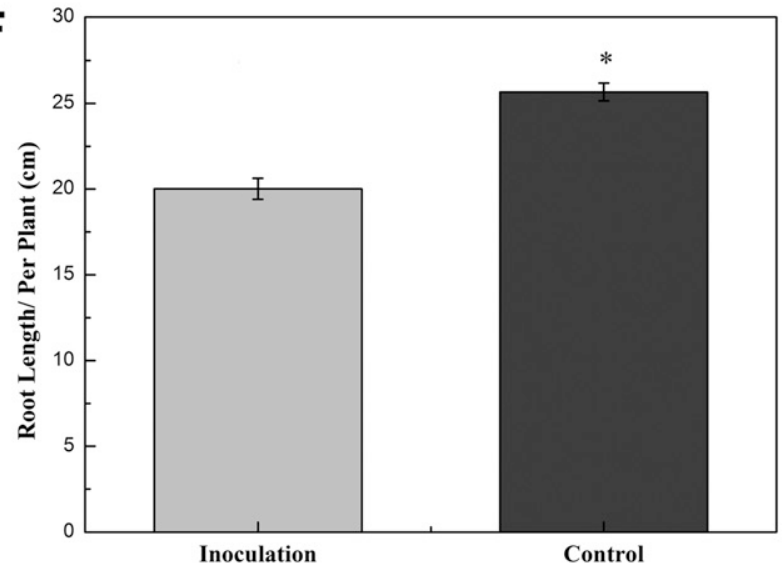

H

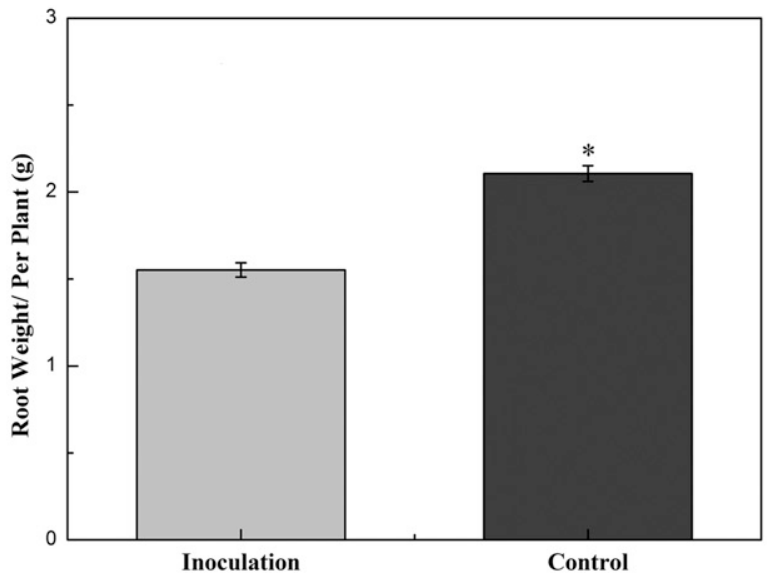

Fig. 5. Comparison of biomass per plant between inoculated alfalfa and controls treated with sterilized water. A and B, The lengths of the hypocotyls and radicles of inoculated and control seeds. C and D, The length of stems and roots of inoculated and control seedlings. $\mathbf{E}$ and $\mathbf{F}$, The length of stems and roots of inoculated mature seedlings (grown for 10 weeks before inoculation) and controls. $\mathbf{G}$ and $\mathbf{H}$, The fresh weights of shoot and root of inoculated mature seedlings and controls. Values are mean \pm standard error (SE), with bars indicating SE. *Significant difference at $P<0.01$ (independent $t$ test). 
$100 \%$ with each sequence of $V$. alfalfae isolate PD489 from the United States in Genbank, and the gene accession numbers obtained from Genbank for use in this study are recorded in Table 3. For the multilocus analyses, the four single-locus datasets did not show any conflicts in tree topology with $70 \%$ support, which allowed them to be combined. The concatenated dataset was composed of $10 \mathrm{Ver}-$ ticillium species (Table 3 ), each with 2,468 characters (nucleotides and gaps), including the ACT region (543) + the EF region (589) + the GPD region (722) + the TS region (614). The best-fit nucleotide substitution model of each gene for ML was calculated by IQ trees. For ACT, the model was HKY $+\mathrm{F}+\mathrm{G} 4$. For EF, the model was $\mathrm{HKY}+\mathrm{F}+\mathrm{I}$. For GPD, the model was $\mathrm{TN}+\mathrm{F}+\mathrm{I}+\mathrm{G} 4$, and for $\mathrm{TS}$, the model was $\mathrm{TN}+\mathrm{F}+\mathrm{G} 4$. Then, ML analyses were conducted using the above-described model of each gene. The multigene tree (Fig. 3) showed that the representative strains from alfalfa in China in this study and $V$. alfalfae from alfalfa from other countries formed a clade with a bootstrap value of 100 , and they were clearly distinguished from the other Verticillium species in this study.

Greenhouse pathogenicity tests. In the first experiment involving the immersion of 50 surface-sterilized seeds in a conidial suspension, 48 of the seeds germinated. Only two seeds did not germinate, and these were coated with mycelium of $V$. alfalfae (Fig. 4A). All 50

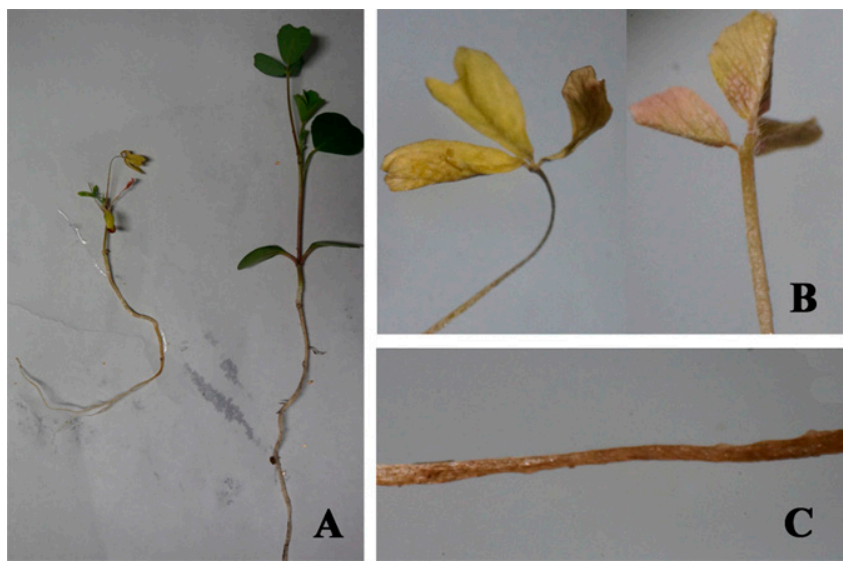

Fig. 6. Alfalfa 4-day-old seedlings inoculated with Verticillium alfalfae after 16 days postinoculation. A, Seedlings were uprooted gently for observation; the seedling on the left was inoculated with $V$. alfalfa, and the seedling on the right is the control. B, Trifoliate leaf of inoculated seedling with chlorosis and necrosis. C, The root of the inoculated seedling with brown discolorations. surface-sterilized seeds that were soaked in sterile water germinated. Those inoculated seeds that germinated had brown discoloration of the radicle, whereas the control seeds had no discoloration (Fig. 4B). The hypocotyl and radicle of inoculated seeds were significantly longer than those of seed treated with sterilized water $(P<0.01)$ (Fig. $5 \mathrm{~A}$ and $\mathrm{B})$. $V$. alfalfae was reisolated from all discolored radicles. No $V$. alfalfae was isolated from controls.

For the second experiment, 38 of 50 seedlings that had been inoculated by dipping the root tips into a conidial suspension had died after transplantation into sterilized vermiculite, and the remaining 12 were close to death. None of the 50 control seedlings died or showed symptoms (Fig. 6A). Symptoms on inoculated seedlings initially appeared on hypocotyls, cotyledons, and true leaves, and subsequently, leaves and petioles became necrotic. Some leaves developed a pinkish orange discoloration (Fig. 6B). The noninoculated seedlings were symptomless. The roots of inoculated seedlings showed brown discoloration (Fig. 6C), whereas roots of the noninoculated control seedlings were white. The lengths of stems and roots of inoculated seedlings were significantly shorter than those of control seedlings exposed only to sterilized water $(P<0.01)$, (Fig. $5 \mathrm{C}$ and D). $V$. alfalfae was reisolated from stems, leaves, and roots of inoculated seedlings, and no $V$. alfalfae was isolated from controls.

In the third experiment, $100 \%$ of seedlings in soil treated with $V$. alfalfae conidia had typical and severe foliar symptoms on more than one stem after 4 weeks postinoculation. The mean disease severity score was 4 , but no dead seedlings were present. All seedlings of the control treatments were healthy and showed no foliar symptoms (Fig. 7A). V. alfalfae was reisolated from the stems of $100 \%$ of the seedlings with foliar symptoms. No $V$. alfalfae was isolated from controls. The symptoms of infected seedlings were the same as those of naturally infected plants in the field. Severe symptoms in infected seedlings were visualized as yellowish or pinkish chlorosis, necrosis, and leaf curling (Fig. 7B). Most of the necrotic and desiccated leaves and petioles had fallen from the stems (Fig. 7C). Transverse sections of the roots inoculated by $V$. alfalfae showed mild brown vessel discoloration, whereas controls were white (Fig. 7D). In addition, hyphae were observed in the xylem tissue of transversely sectioned vascular bundles, but they were absent in the vascular bundles of control plants. There was significant difference in stem length and root length among treatments and controls (Fig. 5 E and F). Shoot and root fresh weights of alfalfa from soils inoculated with $V$. alfalfae were significantly lower than those of sterile water controls $(P<$ 0.01) (Fig. $5 \mathrm{G}$ and $\mathrm{H}$ ).

Wounding effect on infection of $\boldsymbol{V}$. alfalfae. In two experiments, leaflets that had been inoculated after being injured and on plants with inoculated cut stems became chlorotic. No symptoms were
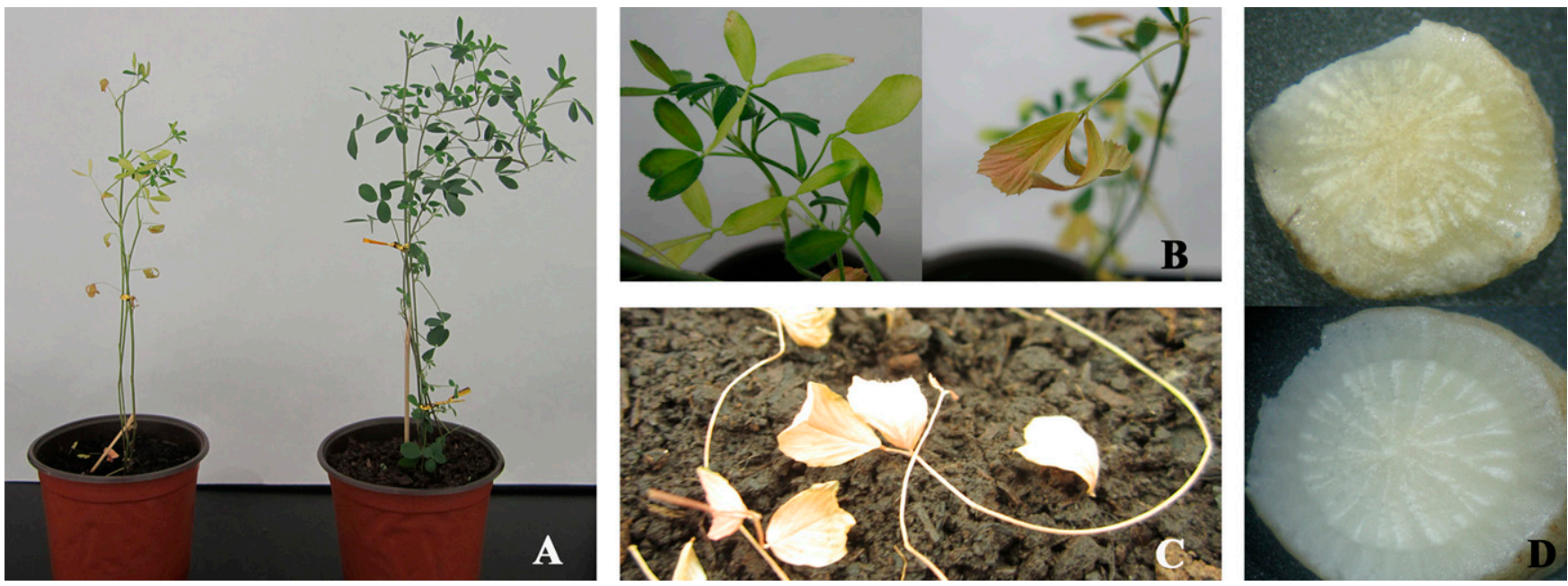

Fig. 7. Alfalfa mature seedlings inoculated with Verticillium alfalfae after 4 weeks postinoculation. A, The seedling on the left is in soil inoculated of $V$. alfalfae inoculum, and the seedling on the right is the control. B and C, Defoliated alfalfa leaves from inoculated plants and chlorotic leaflets with V-shaped tip necrosis. D, Transverse section of the root inoculated by $V$. alfalfae displaying mild brown vessel discoloration (above). The control (below) is white. 
observed on leaflets and stems on which $V$. alfalfae inoculum was applied without any accompanying damage. For stems that had been damaged before the application of inoculum, $V$. alfalfae was isolated from almost $100 \%$ of pieces at locations distant from the stem inoculation site. No $V$. alfalfae colonies developed from the sections of surface-inoculated stems, but colonies developed from the inoculated site with $40.0 \%$ incidence. For the injured and uninjured leaf inoculation treatments, $V$. alfalfae was seldom isolated from stem pieces of both treatments, but it was isolated from about $10.0 \%$ of excised petioles of inoculated injured leaves. $V$. alfalfae was not isolated from excised petioles of inoculated uninjured leaves. $V$. alfalfae was isolated from $100 \%$ of the sites from inoculated injured leaves and $23.3 \%$ of the sites of inoculated uninjured leaves. No V. alfalfae was isolated from water controls.

Host range study of $V$. alfalfae. Four weeks after inoculation with $V$. alfalfae, all plants of the perennial legumes milkvetch, sainfoin, and stylo exhibited symptoms on leaves, becoming chlorotic or necrotic with leaflets curling inward (Fig. 8). Red clover and white clover plants showed no visible symptoms. $V$. alfalfae was successfully reisolated from the stems with chlorotic leaves of milkvetch, sainfoin, and stylo plants, and it was also isolated from stems and roots
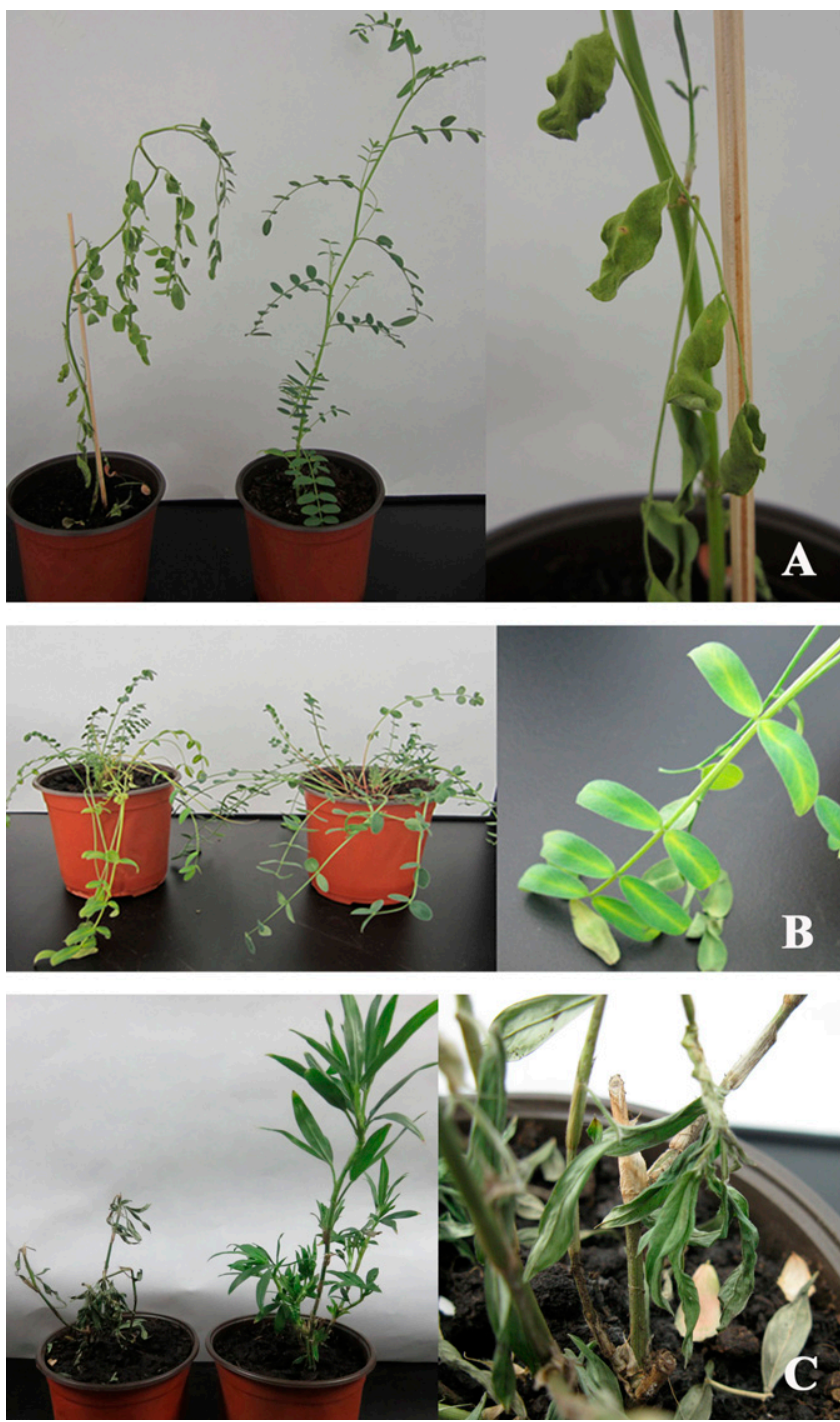

Fig. 8. Reaction of locally grown perennial legume plants to Verticillium alfalfae with foliar Verticillium wilt symptoms after 4 weeks postinoculation. A, The milkvetch seedling on the left was inoculated with $V$. alfalfae, and the seedling on the right is the control. B, The sainfoin seedling on the left was inoculated with V. alfalfae, and the seedling on the right is the control. C, The stylo seedling on the left was inoculated with $V$. alfalfae, and the seedling on the right is the control. The right panels are close-up views of symptoms. of symptomless red and white clover plants that had been inoculated as seedlings. Sterile water-inoculated control plants remained healthy and showed no symptoms. No V. alfalfae was isolated from controls.

\section{Discussion}

Foliar wilt symptoms on alfalfa plants with green stems, morphology-based identification, multigene phylogenies, and pathogenicity testing confirmed that alfalfa fields in or around the closely located Liuxin, Lemin, and Yezhunag villages were infected with $V$. alfalfae. The survey of the distribution of this disease indicates that the pathogen has been able to disperse in high alfalfa-growing regions, with the majority of plants being infected in some fields, whereas in other fields, infected plants are few and scattered. This is the first known occurrence of Verticillium wilt in commercial alfalfa production fields in Lemin and Yezhuang villages. Although this quarantined disease was not found in other nearby or distant alfalfa-growing regions in 2015 based on the foliar wilt symptoms, $V$. alfalfae is thought to be established in some symptomless alfalfa plants in alfalfa in Yezhuang, because in 2016, alfalfa plants with Verticillium wilt symptoms were detected scattered within some alfalfa fields. No report of Verticillium wilt of alfalfa was recorded from China before 2014 (Xu et al. 2016). Therefore, Gansu, China is a new territory of Verticillium wilt of alfalfa. The commercial seed and hay trade has been an important route of regional, national, and international spread of $V$. alfalfae. Although the origin of the primary inoculum of the Gansu outbreak is unknown, we believe that the initial entry of Verticillium wilt of alfalfa into the region with high disease incidence from 2014 is probably through the importation of contaminated seeds. Moreover, a number of the fields in or around Liuxin village exhibiting Verticillium wilt symptoms indicated that the pathogen has spread between fields and infected healthy plants, probably via contaminated farm machinery; residues, spores, mycelium, and possibly, insects (Howard 1985; Huang 2003). Verticillium wilt disease has not been observed in alfalfa plants in provinces outside of Gansu, indicating that only a small amount of contaminated seeds was imported and planted. Hu et al. (2011) and Wang (2010), respectively, reported one alfalfa plant with wilt symptoms in alfalfa nursery fields from Shaxi Province, China, with the pathogen identified as $V$. nigrescens, renamed $G$. nigrescens, but as this pathogen causes distinctive symptoms on alfalfa plants.

Verticillium wilt of alfalfa is a systemic disease, and it can be isolated from most tissues of diseased plants (Christen and Peaden 1981; Isaac 1957). This study has clearly shown the systemic infection, with isolates of $V$. alfalfae obtained with different isolation rates from roots, stems, petioles, and leaves of alfalfa plants, which is consistent with the description of the isolations of the pathogen by Isaac (1957). Calpas and Rahe (1995) and Pennypacker and Leath (1983) found that the pathogen spread through the xylem in a noncontinuous distribution pattern within roots and stems, respectively, whereas two other studies reported a sporadic distribution pattern within leaves, peduncles, pedicels, pods, and seeds (Huang 1989; Huang et al. 1985). This discontinuous distribution pattern provides an explanation of why isolations from roots, stems, and petioles resulted in a higher incidence than isolations from leaves and seeds. Our study also revealed that there was a very low incidence of internal infection of seeds. A previous study also found a very low incidence of seed transmission, with just $0.03 \%$ of one seed lot containing internal $V$. alfalfa, but this was sufficient to provide 750 potential loci of inoculum per hectare (Sheppard 1979).

Isolates of $V$. alfalfae from three regions in Gansu, China formed the same colony characteristics, and there were no significance differences in growth rates, indicating that they may belong to a single strain. The maximum growth of the Gansu isolates occurred at $25^{\circ} \mathrm{C}$, with minimal growth occurring at $30^{\circ} \mathrm{C}$, which was consistent with the findings of Basil and Butler (1991) and Howell and Erwin (1995) of the growth rate of $V$. alfalfae from alfalfa in cool regions. Isolates from warm regions could tolerate relatively higher temperatures as an adaptation to the local conditions (Howell and Erwin 1995). Isolates of $V$. alfalfae may change certain characteristics in 
adapting to new local conditions, but isolates from Gansu, China were similar to cool region isolates. Before a solid taxonomic system provided by Inderbitzin et al. (2011a), most Verticillium species were identified on the basis of their morphological characteristics (in particular, resting structures) as well as single-locus sequences analysis (Karapapa et al. 1997; Nazar et al. 1991). However, the morphological characteristics of a species could change with environmental conditions and culture substrate (Goud et al. 2003), particularly the small morphological differences among $V$. alfalfae, $V$. nonalfalfae, and $V$. albo-atrum (Inderbitzin et al. 2011a). Inderbitzin et al. (2011a) indicated that using combined single-locus datasets to generate multigene phylogenetic trees could provide higher overall support than any of the single-locus phylogenies. In this study, a multigene phylogenetic tree was obtained by analyses of the combined sequences of ex-type isolates with our representative isolates, confirming the taxonomic status of the Verticillium sp. from alfalfa in Gansu, China.

The results of the pathogenicity testing in this study confirmed that $V$. alfalfa infects seeds, seedlings, and fully grown alfalfa plants, with visible chlorotic symptoms occurring in the field. The pathogen also infects seedlings when inoculum is inoculated on seeds, on root tips, and in soil in the greenhouse. Disease symptoms included chlorotic leaves, and $V$. alfalfae was isolated from aboveground tissues of inoculated seedlings. No nodulation bacteria were added to soils during the pathogenicity tests. The protective behavior of symbiotic organisms, such as arbuscular mycorrhizal fungi or Rhizobium spp., could improve the resistance of plants and suppress fungal diseases (Akhtar et al. 2011). Seedlings inoculated with AM fungi had lower incidence of Verticillium wilt in alfalfa than nonmycorrhizal species (Hwang et al. 1992). The biomass of 4-day-old seedlings and 10-week-old seedlings that had been trimmed at 5 weeks and were inoculated by $V$. alfalfae was significantly lower than that for water-inoculated controls, and the severe symptoms and high disease incidence reflected the destructiveness of this disease to the local alfalfa cultivar. Surprisingly, the lengths of the radicle and plumule of seedlings of the inoculated seeds were longer than for developing seedlings of water-treated control seeds. It is likely that $V$. alfalfae could accelerate the germination of embryos and stimulate seedling growth. This is similar to Embellisia astragali on milkvetch seeds (Li and Nan 2007).

No systemic infection resulted from the application of conidial suspensions to undamaged leaflets or stems. With a low frequency, $V$. alfalfae could be isolated from the site of undamaged leaflets, but there was no spread into petioles. $V$. alfalfae could also sometimes be isolated from the site of the application of conidial suspension to stems. In contrast, when conidial inoculum was applied to cut stems or damaged leaflets, $V$. alfalfa was isolated away from inoculum sites, indicating that $V$. alfalfa successfully infected tissues and entered into internal parts of the plant. It seems that wounding of tissue is essential for $V$. alfalfa to infect mature stems and leaves, because no penetration pegs were formed by germinating conidia that would enable penetration into epidermal cells (Jimenez-Diaz and Millar 1986). Moreover, the low isolation incidence from petioles is also consistent with the findings of Jimenez-Diaz and Millar (1986). It seems difficult for the pathogen to enter into the xylem elements of leaflets and stems and systemically colonize the host plant, probably because of the physical barrier provided by the bundle sheath and physiological responses against infection (Fradin and Thomma 2006). However, the leaf veins and petioles of alfalfa with narrower xylem vessels than stems were occasionally plugged with conidia and mycelium (Pennypacker and Leath 1983). The incidence of colonization was much higher by inoculating cut stems, because conidia could directly enter into vascular bundles after the tissue was sliced open. Jimenez-Diaz and Millar (1986) reported that hyphae had the ability to penetrate and grow inside the cuticle without deleterious effects, and that is a likely explanation for the reisolation of $V$. alfalfae from uninjured stems after 4 weeks postinoculation. A phytoalexin, an antimicrobial product that restricts hyphal growth, was purified from alfalfa tissue, and the production from leaves was much higher than that from stems (Khan and Milton 1978). This could explain why the isolation incidence from stems of surface-applied inoculum was higher than that from leaves at the inoculation site.

In contrast to the aboveground tissues, this study found that $V$. alfalfae could enter undamaged roots, resulting in systemic infection and characteristic symptoms. Elango et al. (1986) and Howell and Erwin (1995) also indicated that unwounded root tips exposed to mycelial plugs or conidia suspensions and plants in soil drenched with conidial suspensions developed symptoms of Verticillium wilt. Keinath and Millar (1986) reported that $V$. alfalfae could survive in soils with or without residues and that it survived for long periods on residues after burial. The infection of seedlings in pots containing soil with buried residues indicated again that $V$. alfalfae colonized seedlings via unwounded roots (Keinath and Millar 1986). Huisman (1982) reported that root tips play an important role in initiating root-pathogen interactions, because they diffuse exudates to trigger microbial activity in soil and facilitate the germination of propagules of pathogens and the colonization of plants. Schnathorst (1981) also indicated the exudates seem to originate from root cells in root tips, and exudation also seems to be associated with breaks in the root tip epidermis. All of this evidence confirms that $V$. alfalfae can enter undamaged roots, pass through the endodermis, and traverse into the vascular tissues, causing systemic infection of plants.

This study found that five local perennial legumes could also be carriers of $V$. alfalfae, and it confirmed that asymptomatic hosts can harbor $V$. alfalfae in a biotrophic endophytic phase. Thus, the host range for $V$. alfalfae is almost certainly much larger than previously expected. Some previous cross-infection studies confirmed that $V$. alfalfae isolates are relatively nonhost specific (Busch and Smith 1982; Howell and Erwin 1995). For example, V. alfalfae could naturally infect Catalpa bignonioides, a kind of ornamental tree (Kasson et al. 2014). In fact, a number of other plants could be carriers of $V$. alfalfae with or without symptoms. Soybean (Glycine max), peanut (Arachish ypogaea), eggplant (Solanum melongena), and black mustard (Brassica nigra) were shown to be susceptible to $V$. alfalfae with foliar Verticillium symptoms, whereas common groundsel (Senecio vulgaris), tomato (Lycopersicon esculentum), and dandelion (Taraxacum officinale) hosted $V$. alfalfae with mild or no foliar symptoms (Busch and Smith 1982; Howell and Erwin 1995).

In conclusion, the findings presented here confirm that $V$. alfalfae has already become established in some regions of Gansu, China and that this quarantined disease is a risk to the alfalfa industry in China. Seeds, hay, and residues from infected alfalfa field crops, especially when applied and spread during the establishment of new crops, along with farm machinery that had been on infected fields are the most likely sources of inoculum leading to serious Verticillium wilt disease outbreaks. Insects are also a possible way for the pathogen to spread from infected to healthy alfalfa plants in suitable conditions (Huang et al. 1983). There is a need for careful monitoring of each alfalfa-producing area to identify the presence of Verticillium wilt and ensure that there are minimal economic consequences from the spread of $V$. alfalfae. Cultivars of alfalfa with resistance to this pathogen need to be introduced to prevent severe losses of yield, because all local Chinese cultivars are very susceptible to this disease (Huang et al. 1999).

\section{Acknowledgment}

We thank the anonymous reviewers of the manuscript.

\section{Literature Cited}

Akhtar, M. S., Siddiqui, Z. A., and Wiemken, A. 2011. Arbuscular mycorrhizal fungi and Rhizobium to control plant fungal diseases. Pages 263-292 in: Alternative Farming Systems, Biotechnology, Drought Stress and Ecological Fertilisation. E. Lichtfouse, ed. Springer, Dordrecht, The Netherlands.

Atkinson, T. G. 1981. Verticillium wilt of alfalfa: Challenge and opportunity. Can J. Plant Pathol. 3:266-272.

Basil, P. K., and Butler, G. 1991. Colony growth response to temperature and pathogenicity of isolates of Verticillium albo-atrum from alfalfa in Canada Can. J. Plant Pathol. 13:112-115.

Busch, L. V., and Smith, E. A. 1982. Reaction of a number of cultivated plants and weed species to an alfalfa isolate of Verticillium albo-atrum. Can. J. Plant Pathol. 4:266-268.

Calpas, J. T., and Rahe, J. E. 1995. Distribution of Verticillium albo-atrum in the root systems of resistant and susceptible alfalfa plants. Can. J. Plant Pathol. 17:240-246. 
Christen, A. A., and Peaden, R. N. 1981. Verticillium wilt in alfalfa. Plant Dis. 65: 319-321.

Christen, A. A., Peaden, R. N., Harris, G. P., and Heale, J. B. 1983. Virulence of north American and European isolates of Verticillium albo-atrum on alfalfa cultivars. Phytopathology 73:1051-1054.

Elango, D., Robb, J., Newcombe, G., and Bush, L. V. 1986. Growth pouch technique for the observation of cellular interactions between alfalfa seedling roots and Verticillium albo-atrum. Can. J. Plant Pathol. 8:78-84.

Erwin, D., and Howell, A. 1998. Verticillium survives heat in Mojave Desert alfalfa. Calif. Agric. 52:24-26.

Fradin, E. F., and Thomma, B. P. H. J. 2006. Physiology and molecular aspects of Verticillium wilt diseases caused by $V$. dahliae and $V$. albo-atrum. Mol. Plant Pathol. 7:71-86.

Ghalandar, M., Clewes, E., Barbara, D. J., Zare, R., and Heydar, A. 2004. Verticillium wilt (Verticillium albo-atrum) on Medicago sativa (alfalfa) in Iran. Plant Pathol. 53:812.

Gilbert, R. G., Peaden, R. N., and Ford, W. P. 1988. Verticillium wilt of alfalfa. Plant Pathol. 53:81-82.

Gordon, T. R., Corell, J. C., Gilchrist, D. G., and Martensen, A. N. 1989. Verticillium wilt to alfalfa in California. Plant Dis. 73:18-20.

Goud, J. K. C., Termorshuizen, A. J., and Gams, W. 2003. Morphology of Verticillium dahliae and $V$. tricorpus on semi-selective media used for the detection of $V$. dahliae in soil. Mycol. Res. 107:822-830.

Graham, J. H., Peaden, R. N., and Evans, D. W. 1977. Verticillium wilt of alfalfa found in the United States. Plant Dis. 61:337-340.

Harvey, I. C. 1982. Assessment keys for some crown and root diseases of lucerne (Medicago sativa L.). N. Z. J. Exp. Agric. 10:317-322.

He, X. T. 2013. China Grass Industry Statistics. National Animal Husbandry Terminus, Beijing, China.

Hedlund, T. 1923. Om Nagrasjukdomar och skador pa vara lantbruksvaxter. Sver. Allm. Jordbrukstidskr. 5:166-168.

Hoang, D. T., Chernomor, O., Haeseler, A., Minh, B. Q., and Le, S. V. 2018. UFBoot2: Improving the ultrafast bootstrap approximation. Mol. Biol. Evol. 35:518-522.

Howard, R. J. 1985. Local and long-distance spread of Verticillium species causing wilt of alfalfa. Can. J. Plant Pathol. 7:199-202.

Howell, A. B., and Erwin, D. C. 1995. Characterization and persistence of Verticillium albo-atrum isolated from alfalfa growing in high temperature regions of southern California. Plant Pathol. 44:734-748.

Hu, X. P., Wang, M. X., Hu, D. F., and Yang, J. R. 2011. First report of wilt on alfalfa in China caused by Verticillium nigrescens. Plant Dis. 95:1591.

Huang, H. C. 1989. Distribution of Verticillium albo-atrum in symptomed and symptomless leaflets of alfalfa. Can. J. Plant Pathol. 11:235-241.

Huang, H. C. 2003. Verticillium wilt of alfalfa: Epidemiology and control strategies. Can. J. Plant Pathol. 25:328-338.

Huang, H. C., Acharya, S. N., Hou, T. J., Erickson, R. S., Dalton, R. E., and Mueller, C. A. 1999. Susceptibility of Chinese alfalfa cultivars to Verticillium wilt. Plant Pathol. 8:67-72.

Huang, H. C., Hanna, M. R., and Kokko, E. G. 1985. Mechanisms of seed contamination by Verticillium albo-atrum in alfalfa. Phytopathology 75:482-488.

Huang, H. C., Harper, A. M., Kokko, E. G., and Howard, R. J. 1983. Aphid transmission of Verticillium albo-atrum to alfalfa. Can. J. Plant Pathol. 5:141-147.

Huisman, O. C. 1982. Interrelations of root growth dynamics to epidemiology of root-invading fungi. Annu. Rev. Phytopathol. 20:303-327.

Hwang, S. F., Chang, K. F., and Chakravarty, P. 1992. Effect of vesiculararbuscular fungi on the development of Verticillium and Fusarium wilt of alfalfa. Plant Dis. 76:239-243.

Inderbitzin, P., Bostock, R. M., Davis, R. M., Usami, T., Platt, H. W., and Subbarao, K. V. 2011a. Phylogenetics and taxonomy of the fungal vascular wilt pathogen Verticillium, with the descriptions of five new species. PLoS One 6:e28341.
Inderbitzin, P., Davis, R. M., Bostock, R. M., and Subbarao, K. V. 2011b. The ascomycete Verticillium longisporum is a hybrid and a plant pathogen with an expanded host range. PLoS One 6:e18260.

Isaac, I. 1957. Wilt of lucerne caused by species of Verticillium. Ann. Appl. Biol. 45:550-558.

Jasjeet, D., Pankaj, K., Tiwari, B. N., and Rakesh, P. 2011. Chemopharmacological aspects of alfalfa: A review. J. Adv. Sci. Res. 2:50-53.

Jimenez-Diaz, R. M., and Millar, R. L. 1986. Lack of systemic colonization of alfalfa plants after inoculation of uninjured leaves with conidia of Verticillium albo-atrum. Plant Dis. 70:509-515.

Karapapa, V. K., Bainbridge, B. W., and Heale, J. B. 1997. Morphological and molecular characterization of Verticillium longisporum comb. nov., pathogenic to oilseed rape. Mycol. Res. 101:1281-1294.

Kasson, M. T., Short, D. P. G., O'Neal, E. S., Subbarao, K. V., and Davis, D. D. 2014. Comparative pathogenicity, biocontrol efficacy, and multilocus sequence typing of Verticillium nonalfalfae from the invasive Ailanthus altissima and other hosts. Phytopathology 104:282-292.

Katoh, K., and Standley, D. M. 2013. MAFFT multiple sequence alignment software version 7: Improvements in performance and usability (Outlines version 7). Mol. Biol. Evol. 30:772-780.

Keinath, A. P., and Millar, R. L. 1986. Persistence of an alfalfa strain of Verticillium albo-atrum in soil. Phytopathology 76:576-581.

Khan, F. Z., and Milton, J. M. 1978. Phytoalexin production and the resistance of lucerne (Medicago sativa L.) to Verticillium albo-atrum. Physiol. Plant Pathol. 13:215-221.

Kreitlow, K. W. 1962. Verticillium wilt of alfalfa. A destructive disease in Britain and Europe not yet observed in the United States. U.S. Dep. Agric. Agric. Res. Serv. 34:1-15.

Li, Y. Z., and Nan, Z. B. 2007. Symptomology and etiology of a new disease, yellow stunt, and root rot of standing milkvetch caused by Embellisia sp. in Northern China. Mycopathologia 163:327-334.

Mason-Gamer, R. J., and Kellogg, E. A. 1996. Testing for phylogenetic conflict among molecular data sets in the tribe Triticeae (Gramineae). Syst. Biol. 45: 524-545.

McLaren, A. D., Luse, R. A., and Skujins, J. J. 1962. Sterilization of soil by irradiation and some further observations on soil enzyme activity 1. Soil Sci. Soc. Am. J. 26:371-377.

Nazar, R. N., Hu, X., Schmidt, J., Culham, D., and Robb, J. 1991. Potential use of PCR-amplified ribosomal intergenic sequences in the detection and differentiation of Verticillium wilt pathogens. Physiol. Mol. Plant Pathol. 39:1-11

Nguyen, L.-T., Schmidt, H. A., Von Haeseler, A., and Minh, B. Q. 2014. IQTREE: A fast andeffective stochastic algorithm for estimating maximumlikelihood phylogenies. Mol. Biol. Evol. 32:268-274.

Peaden, R. N., Gilbert, R. G., and Christen, A. A. 1985. Control of Verticillium albo-atrumon alfalfa. Can. J. Plant Pathol. 7:511-514.

Pennypacker, B. W., and Leath, K. T. 1983. Dispersal of Verticillium albo-atrum in the xylem of alfalfa. Plant Dis. 67:1226-1229.

Sato, R. 1994. Outbreak of alfalfa Verticillium wilt in Hokkaido. Jpn. Agric. Res. Q. 28:44-51.

Schnathorst, W. C. 1981. Life cycle and epidemiology of Verticillium. Pages 81-111 in: Fungal Wilt Diseases of Plants. M. E. Mace, A. A. Bell, and C. H. Beckman, eds. Academic Press, New York, NY.

Sheppard, J. W. 1979. Verticillium wilt, a potentially dangerous disease of alfalfa in Canada. Can. Plant Dis. 59:60.

Shi, S., Nan, L., and Smith, K. F. 2017. The current status, problems, and prospects of Alfalfa (Medicago sativa L.) breeding in China. Agronomy (Basel) 7:1-11

Wang, M. X. 2010. Verticillium nigrescens from alfalfa and its pathogenicity. MSc dissertation. Northwest A \& F University, Yangling, China.

Xu, S., Li, Y. Z., and Nan, Z. B. 2016. First report of Verticillium wilt of alfalfa caused by Verticillium alfalfae in China. Plant Dis. 100:220. 